\title{
TERRITORIALIDADES ORIGINÁRIAS E A COSMOLOGIA KAIOWÁ E GUARANI: AUTO-ORGANIZAÇÃOO CONTRA O AGRONEGÓCIO, OS CRIMES SOCIOAMBIENTAIS E A PANDEMIA
}

\author{
ELIEL BENITES ${ }^{1}$ \\ $U F G D, B R A S I L$ \\ https://orcid.org/0000-0002-0034-4589 \\ GISLAINE MONFORT ${ }^{2}$ \\ UFGD, BRASIL \\ https://orcid.org/0000-0002-5677-5740 \\ LAURA JANE GISLOTI ${ }^{3}$ \\ $U F G D, B R A S I L$ \\ http://orcid.org/0000-0002-3954-0245
}

\begin{abstract}
RESUMO: Na região sul do estado de Mato Grosso do Sul os povos Kaiowá e Guarani constroem uma luta incessante contra a usurpação de seus territórios tradicionais pelas fronteiras extrativistas do agronegócio que é dominante na região. Nesse sentido, a pandemia da Covid-19 fez emergir profundas reflexões, narrativas e ações frente a mais um contexto de enfrentar o paradoxo de sobreviver às epidemias pelas quais não foram responsáveis. Desta forma, buscamos tecer e compartilhar algumas reflexões que, por um lado, evidenciem elementos sobre a cosmologia, a biopolítica e a geopolítica da pandemia e, por outro lado, demonstrem as múltiplas estratégias de resistência frente ao agronegócio e no enfrentamento à Covid-19. Metodologicamente, reunimos referenciais teóricos a partir de um levantamento bibliográfico que teve como referência as lutas socioterritoriais e a cosmologia Kaiowá e Guarani contra a pandemia, o colonialismo, o Estado e os crimes do agronegócio. Objetivando aprofundar o diálogo e ampliar a construção de conhecimentos, apresentamos, no desenvolvimento final dos resultados e discussão, uma passagem a respeito da ótica Kaiowá e Guarani sobre saúde, doenças e pandemia.
\end{abstract}

PALAVRAS-CHAVE: cosmologia, conhecimento tradicional, doença.

ABSTRACT: In the southern region of the state of Mato Grosso do Sul, the Kaiowá and Guarani peoples are building an incessant struggle against the usurpation of their traditional territories by the extractive frontiers of agribusiness that is dominant in the region. In this sense, the Covid19 pandemic has given rise to deep reflections, narratives and actions in the face of yet another context of facing the paradox of surviving epidemics for which they were not responsible. In this way, we seek to weave and share some reflections that, on the one hand, show elements about the

\footnotetext{
1 Doutorando no Programa de Pós-Graduação em Geografia (PPGG/UFGD). E-mail: elielbenites@ufgd.edu.br

$\frac{2}{2}$ Mestranda no Programa de Pós-Graduação em Geografia (PPGG/UFGD). E-mail: gislainecmonfort@gmail.com

${ }_{3}^{3}$ Professora do Programa de Pós-graduação em Educação e Territorialidade (PPGET/FAIND) e do Programa de Pós-graduação em Entomologia e Conservação da Biodiversidade (PPGECB/FCBA). E-mail: lauragisloti@gmail.com
} 
Espaço Ameríndio

cosmology, biopolitics and geopolitics of the pandemic and which, on the other hand, demonstrate the multiple resistance strategies against agribusiness and in facing Covid-19. Methodologically, we gathered theoretical references, based on a bibliographical survey that had as references the socio-territorial struggles and the Kaiowá and Guarani cosmology against the pandemic, colonialism, the State and crimes of agribusiness. In order to deepen the dialogue and expand the construction of knowledge, we present in the final development of the results and discussion a vision about the Kaiowá and Guarani perspective on health, diseases and pandemic.

KEYWORDS: cosmology, traditional knowledge, disease. 


\section{Introdução}

A pandemia ocasionada pelo novo coronavírus, SARS CoV-2, causador da doença Covid-19, revelou como a saúde humana é intimamente interligada com a forma como nos relacionamos com o ambiente. Toda essa dinâmica de doenças e saque à biodiversidade está relacionada a um amplo processo de expansão da devastação de habitats, territórios e ecossistemas diversos e saudáveis para o avanço da fronteira extrativista.

O predatismo colonial e capitalista tem devastado territórios de vida de diversas populações e tem esgotado habitats vitais inteiros, colocando cada vez mais espécies em risco, incluindo a própria espécie humana. Assim, é possível refletir sobre a possibilidade de que pandemias podem estar relacionadas a uma reação do planeta Terra, tão doente e maltratado diante das graves agressões desferidas pelas mentes e mãos da sociedade das mercadorias, cuja falta de sabedoria e de humanidade transformou a natureza em produto e recurso (PAVÃO et al., 2021 a).

Nesse sentido, povos indígenas enfrentam uma vez mais o paradoxo de terem que lutar contra doenças pelas quais não foram responsáveis - frente ao massacre causado pela doença dos brancos, desenvolveram, ao longo dos séculos, inúmeras estratégias autônomas de cuidado coletivo baseadas nos próprios saberes e formas de organização. No contexto da atual pandemia da Covid-19 vivemos uma das maiores crises humanitárias em escala global e que no Brasil tem sido associado a uma gestão irresponsável do Estado que é conivente com a banalização das mortes e, sobretudo, com a expansão da doença em territórios indígenas através das redes de contágio de não-indígenas como, por exemplo, as invasões de garimpeiros, do agronegócio, da mineração e outros.

Diante disso, aspectos sobre a pandemia e a emergência de novos vírus têm sido exaustivamente analisados e debatidos na academia. No entanto, é evidente que a pandemia é fruto de séculos de saques à natureza e que todo esse movimento predatório aprofunda múltiplas crises como a social, a política e a ecológica, demonstrando as relações de poder e de dominação do capital sobre os territórios, corpos e diversas formas de vida. Intensificando também as crises estruturais que se sustentam no genocídio dos povos indígenas, do povo preto e do povo pobre (MARTINS et al., 2020).

Eis a dinâmica da política da morte, ou necropolítica, sustentada na dimensão da racialização, em que o monopólio de poder do Estado age a fim de determinar quem vive e quem morre. Nesse sentido, o colonialismo, o racismo e a violência de Estado estão articulados para subjugar a vida ao poder da morte, um processo que tem sido associado aqui à usurpação dos territórios originários por corporações nacionais e transnacionais extrativistas do agronegócio que têm devastado e destruído ecossistemas inteiros, gerando impactos irreversíveis em nome da exploração, do lucro e da ganância (MBEMBE, 2003, SHIVA, 2003; KRENAK, 2015; MBEMBE, 2018). 
O Estado brasileiro, tanto na gestão de governos de direita como nos ditos da esquerda progressista, sempre esteve alinhado à economia política extrativista e às políticas neoliberais em detrimento do reconhecimento da diversidade sociocultural e do reconhecimento dos direitos originários dos territórios indígenas. Depois de mais de uma década de conciliação de classes, de intensificação de investimentos no agronegócio e nos megaprojetos, chegamos ao abismo no qual nos encontramos: sob a política de um governo reacionário, genocida, desumano e anti-indígena que segue intensificando a agenda de ataques aos povos originários. Nesse sentido, a perversa expansão da degradação ambiental sobre territórios, ecossistemas, biomas (a exemplo do Pantanal e da Amazônia nos últimos anos) e o avanço de políticas genocidas durante a crise de saúde global, são ações que fazem parte de um regime de poder fomentado pelo Estado e pelos distintos governos que ocuparam os poderes institucionais (MARTINS et al., 2020).

Frente a isso, em um cenário de intenso domínio do agronegócio como na região centro-oeste do Brasil, no sul do estado do Mato Grosso do Sul, a situação dos povos Kaiowá e Guarani não tem sido diferente dos demais povos indígenas da América Latina na luta contra esse modelo predatório e contra a pandemia. Há uma imensa preocupação com o aumento avassalador dos casos e óbitos registrados e, desde o início, os povos, através de diferentes organizações indígenas, responsabilizam e denunciam o Estado e os órgãos governamentais de Saúde pela tragédia amplamente anunciada (AMADO e RIBEIRO, 2020).

Nesse contexto, o grande cerne das violências contra os Kaiowá e Guarani está no regime de poder em que o Estado fomenta a precariedade territorial e os crimes socioambientais do agronegócio que são pagos com as vidas dos povos. Esses massacres são conduzidos por várias maneiras pelas quais se exerce o poder de matar, seja através da intensa degradação ambiental dos territórios indígenas para expansão do agronegócio e das outras formas de extrativismo, seja pela pandemia ou pelo uso de grupos paramilitares por setores ruralistas (milícias/seguranças privados) e órgãos repressores do Estado, como a Força Nacional e a Polícia Militar (MONFORT e GISLOTI, 2020).

De fato, a atual pandemia é um produto desse sistema perverso e predatório, cujo projeto de poder é denunciado e combatido há séculos pelos povos indígenas, os quais resistiram e resistem potencializando suas formas de ser, viver e lutar. Essa resistência é construída através de cosmologias fundamentadas em uma visão sistêmica, holística e orgânica que integra os territórios, os sistemas socioecológicos, a espiritualidade e os conhecimentos ancestrais que potencializam as formas de ser e viver, a autonomia, o fortalecimento étnico-cultural e o cuidado com a fauna e a flora. Os povos indígenas, aos seus modos, tempos e espaços, pautam a defesa da Terra-Território e destacam que a Mãe Terra também depende de suas guardiãs e guardiões, os povos originários, pois esses não sucumbiram nas mãos da ganância e do progresso ilusório dos governos (VERON, 2018).

Desse modo, sabemos que os territórios em que ainda se encontram grande conservação da diversidade biológica, são 
precisamente territórios em que estão os povos indígenas (GARNETT et al., 2018), mesmo que estes sejam caracterizados por pequenos fragmentos como no caso do sul de Mato Grosso do Sul. Essas relações caracterizam a resistência política alicerçada na diversidade cultural e socioterritorial contra a racionalidade monocultural das fronteiras do agronegócio. Entender esses processos considerando as dimensões socioterritoriais, ecológicas e cosmológicas nos possibilita demonstrar os conflitos e as relações de poder e contrapoder com a resistência e as complexas relações que são parte da revolução teórica e política que insurge no âmago dos movimentos étnico-socioterritoriais dos povos originários.

Diante disso, é relevante se atentar para o fato de que o Mato Grosso do Sul é um dos estados que possuem as maiores concentrações de territórios nas mãos do agronegócio e mais de 90\% são territórios privados ${ }^{4}$. A monopolização das terras, associada ao modelo predatório do neoextrativismo, tem produzido sistematicamente um amplo aprofundamento do etnocídio, da devastação ambiental, da precarização territorial e da superexploração de trabalho. Compreender estas relações é fundamental para que se entenda quem são os ignorantes causadores da desastrosa devastação socioecológica e do surgimento de diversos patógenos (KOPENAWA e ALBERT, 2015; KRENAK, 2018).

Contudo, no âmago desse profundo e complexo processo de violência, conflitos territoriais e resistência, os povos Kaiowá e Guarani fortalecem as lutas anticoloniais em distintos territórios através das organizações comunitárias e dos movimentos étnico-socioterritoriais, como os conselhos Aty Guasu, Kuñangue Aty Guasu e Retomada Aty Jovem (RAJ). Entre outros exemplos de organizações e coletivos estão a associação cultural ASCURI, as ações da Unidade Experimental da aldeia Teý'ikuê, no município de Caarapó e a experiência agroflorestal da escola espiritual Xiru Karai, do tekoha Panambizinho no município de Dourados. Essas iniciativas se alicerçam na cosmologia, nos conhecimentos ancestrais, nas práticas de manejo tradicional e nos saberes Kaiowá e Guarani. E ainda é preciso destacar que, no contexto de pandemia, estes povos fortaleceram os processos de auto-organização e autonomia territoriais através do levantamento de barreiras sanitárias, da construção de redes de campanhas de solidariedade, apoio mútuo e fortalecimento da espiritualidade (MONFORT e GISLOTI, 2020).

Diante disso, buscamos compartilhar algumas reflexões sobre a biopolítica da doença, a geopolítica e a percepção cosmológica de um pesquisador Kaiowá sobre a pandemia e suas relações com a devastação ocasionada pelo agronegócio. Como metodologia reunimos referenciais teóricos e apresentamos a discussão a partir de levantamento bibliográfico, de conhecimentos transdisciplinares e do diálogo intercultural crítico, tendo como referências as territorialidades originárias e a cosmologia destes povos frente aos crimes

\footnotetext{
${ }^{4}$ SANCHEZ, Izabela. Com $92 \%$ do território privado, MS tem maior concentração de terras particulares do país. De olhos nos ruralistas, 11/04/2017. Disponível em: $<$ https://deolhonosruralistas.com.br/2017/04/11/com-92-territorio-privado-ms-tem-maior-concentracaode-terras-particulares-pais/ > . Acesso em: 20/03/21.
} 
socioambientais do agroextrativismo e diante da pandemia. Assim, estruturamos o texto a partir de três categorias: (i) Faces dos crimes socioambientais do agronegócio e os caminhos das lutas territoriais Kaiowá e Guarani; (ii) Ações políticas autônomas e autogestão territorial Kaiowá e Guarani frente à pandemia; e (iii) A ótica Kaiowá e Guarani: saúde, doença, pandemia e resistências.

Dessa forma, utilizamos a abordagem qualitativa a fim de tecermos relações entre a literatura disponível, a transdisciplinaridade e o diálogo intercultural com um pesquisador Kaiowá, de modo que fosse possível rediscutir criticamente a construção dos conhecimentos sobre as dinâmicas territoriais e os crimes socioambientais causados pelo agronegócio no Mato Grosso do Sul. E em frente a isso, pensar as relações de contrapoder e resistência anticolonial construídas pelos povos. Por fim, apresentamos a discussão a partir do ponto de vista Kaiowá e Guarani sobre saúde, doenças e o surgimento de epidemias/pandemias.

Há muitos trabalhos que tem buscado a compreensão e percepção dos povos sobre a pandemia. Contudo, poucos são os que enfatizam a perspectiva cosmológica e a autoafirmação ontológica-política. Neste trabalho nos pautamos nessa abordagem que redimensiona as perspectivas interculturais destacando uma visão simétrica entre as ciências, rompendo com a colonialidade do saber que predomina na visão ocidental. Desse modo, a ciência ocidental seria apenas outro saber possível e passível de diálogo "para acompanhar e compreender as mudanças da realidade da aldeia e atuar sobre ela com uma visão crítica" (BENITES, 2014, p. 28).

Assim, a elaboração da pesquisa em colaboração e co-autoria com um pesquisador Kaiowá se alinha à perspectiva de construção do conhecimento cosmocentrado nos mundos diversos e plurais, nas ciências e óticas indígenas. Essas ciências têm sido protagonizadas nas pesquisas construídas por pesquisadoras e pesquisadores que reelaboram os saberes, as lutas, as histórias e trajetórias de seus povos, a partir do trabalho junto à suas comunidades e na multiplicidade dos modos de ser, dos saberes e territórios, rompendo com os cercos da visão una e a "mono-cultura" da universidade, além de fortalecer a autoafirmação e a autoexpressão da religiosidade/espiritualidade Guarani e Kaiowá como uma dimensão da ciência nativa.

Nesse sentido, finalizamos essa reflexão com o pensamento do antropólogo Kaiowá Celuniel Valiente, que reflete a mudança do paradigma acadêmico: os povos indígenas antes vistos como interlocutores das pesquisas passam a ocuparem o papel de indígenas pesquisadores e pesquisadoras, protagonistas de seus próprios trabalhos junto ao povo:

A ciência indígena não pode ser caracterizada menos do que a ciência Ocidental, mas sim pensada na interação ou no diálogo entre esses diferentes conhecimentos que existem no mundo. Também, é preciso tirar os conhecimentos indígenas da concepção tradicional, ou seja, descartar da esfera da antiguidade ao qual se 
percebe como antigo e ultrapassado; num olhar mais profundo desses conhecimentos, percebe-se o valor epistemológico que ele possui. Da mesma forma, as produções científicas de indígenas nas universidades, devemos olhar esses trabalhos como uma outra forma de pensar e fazer antropológico (VALIENTE, 2018, p.202)

\section{Faces dos crimes socioambientais do agronegócio e os caminhos das lutas territoriais Kaiowá e Guarani}

Vivemos o aprofundamento do processo de precarização territorial, degradação ambiental e crise ecológica ocasionada principalmente pela lógica de acumulação por espoliação, produção destrutiva e ampliação das fronteiras extrativistas. E as áreas provedoras de vidas na América Latina são, em grande parte, ecossistemas e territórios em que estão povos indígenas, os quais têm sido profundamente impactados pelo avanço das monoculturas (ORTIZ e MEZA, 2020).

O estado do Mato Grosso do Sul possui a segunda maior população indígena do Brasil com oito etnias em luta pelo território: Guarani Kaiowá; Guarani Ñandeva; Terena; Atikum; Guató; Kadiwéu; Ofaié e Kinikinau (CHAMORRO \& COMBÈS, 2015). Esta pesquisa é construída junto aos povos Guarani Kaiowá e Guarani Ñandeva, os quais se autodenominam Kaiowá e Guarani ou Guarani e Kaiowá, que possuem uma população estimada em mais de 50 mil pessoas (PEREIRA, 2016). E seus territórios originários se estendem da Serra de Maracaju, ao sul, banhado pela bacia do rio Paraná e ao norte até o rio Apa.

Essa dimensão foi bastante reduzida pelas políticas do Estado e do extrativismo, ocupando atualmente pequenas áreas situadas entre a zona de fronteira do Brasil com o Paraguai (VALIENTE, 2019). A maior parte das pessoas vive hoje nas oito reservas indígenas em pequenas ilhas de terras criadas pelo indigenismo de Estado através do Serviço de Proteção ao Índio (SPI), que teve como objetivo estabelecer um regime de cercamento e precarização territorial para os povos indígenas que estavam sendo expulsos brutalmente de seus tekoha. Esse mesmo período está associado ao aumento do desmatamento e da devastação ambiental visando a exploração da terra e a monopolização com os latifúndios para pecuária e, posteriormente, a instalação do agronegócio (BENITES, 2020).

Além das reservas, ainda há coletivos que vivem também em Terras Indígenas demarcadas, acampamentos à beira de rodovias e retomadas territoriais. Nesse sentido, estão territorializados em 22 áreas indígenas, incluindo as oito reservas e as quatorze terras indígenas (Figura 1). 
Figura 1 - Localização dos territórios atuais dos povos Guarani e Kaiowá no Mato Grosso do Sul, Brasil.

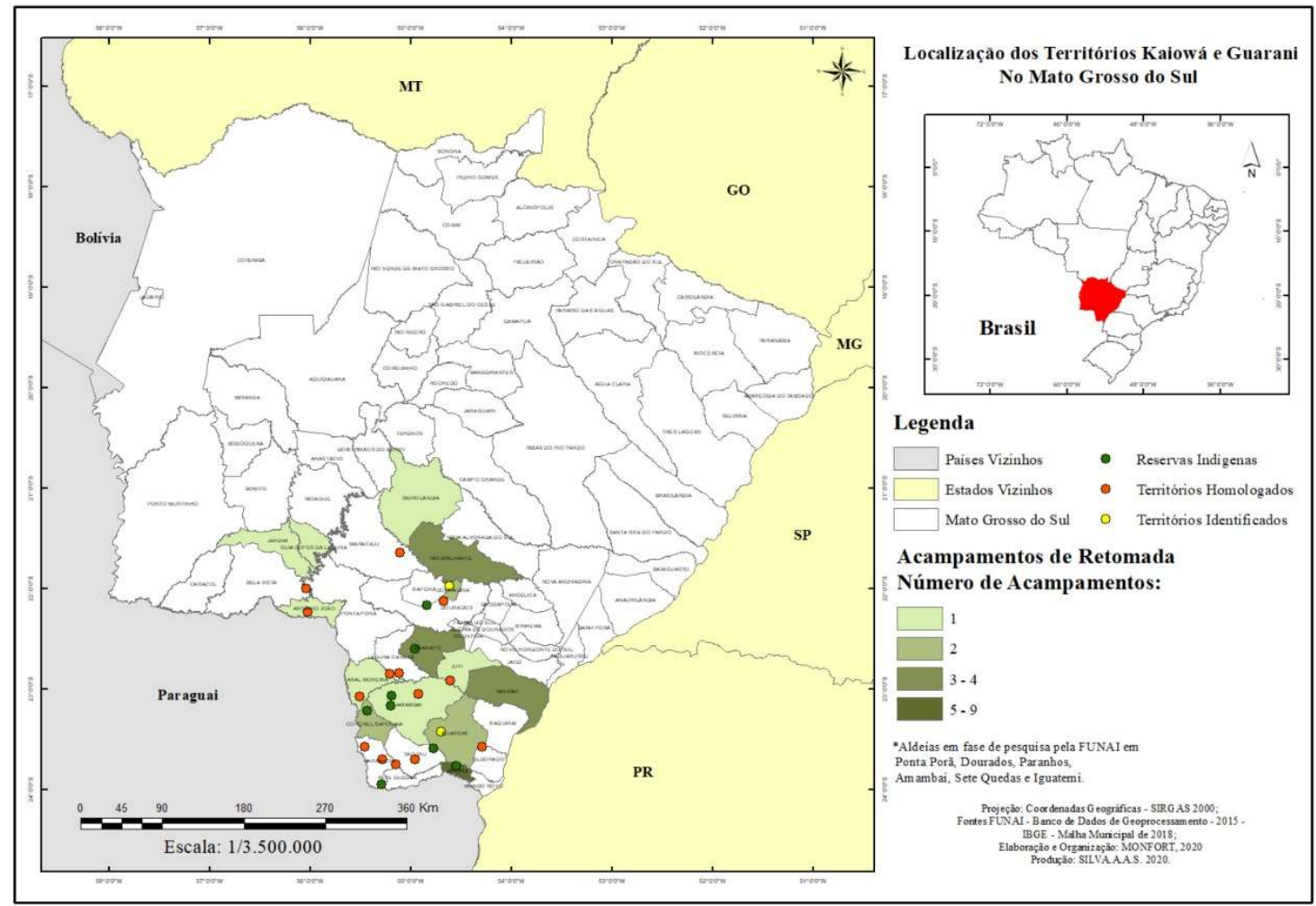

Fonte: Monfort e Gisloti (2020)

Contudo, desde o final da década de 1970, o número de áreas ocupadas por esses povos vem se ampliando gradativamente e esse fato tem ocorrido a partir da reorganização dos movimentos autônomos que passaram a ampliar o processo de auto-organização e a reivindicar a demarcação e autodemarcação de territórios tradicionais saqueados pela ocupação colonialista (BENITES, 2012; BENITES, 2020).

Esses processos de retomada se opõem aos territórios monopolizados pela monocultura transgênica com a soja e o milho, além da cana-de-açúcar para biocombustível e de setores da agroindústria que, aliás, são os principais setores que potencializam a superexploração e a degradação sistêmica do trabalho, principalmente de pessoas indígenas nas usinas, nos cortes de cana e nos complexos industriais, além de ser um dos vetores centrais da precarização territorial, degradação ambiental e produção de doenças (MARTINS et al., 2020).

O agronegócio como agente da morte e precarização ficou mais evidente neste período de pandemia. Os primeiros casos de Covid-19 entre os povos indígenas do estado de Mato Grosso do Sul foram relatados em moradores da Reserva Indígena no município de Dourados e na Reserva indígena Te'yí kue em Caarapó. Essas pessoas trabalhavam em unidades da BRF S.A. (fusão entre Sadia e Perdigão), da Seara Alimentos Ltda. (JBS), e da Raízen (fusão entre as multinacionais Shell e Cosan) que incide ainda sobre a Terra Indígena Guyraroká. Dessa maneira, os frigoríficos, assim como as usinas, como parte das atividades agroindustriais que usurpam os territórios Kaiowá e Guarani, foram o 
epicentro de propagação inicial do vírus, assim como ocorreu em outros municípios do país (MONFORT e GISLOTI, 2020).

É fato que grande parte das doenças que surgiram nas últimas cinco décadas tiveram origem em animais silvestres, a exemplo da gripe suína, a gripe aviária e, agora o novo coronavírus - vírus estes que viviam dentro de um ciclo ecossistêmico equilibrado, mas que têm se tornado grande ameaça à população humana por meio do amplo processo de crise ecológica e devastação de habitats e territórios saudáveis. Quando as ações de determinadas sociedades ferem esse ciclo com interferência nas dinâmicas ecológicas, são propiciadas as condições ideias para que os vírus apresentem grande capacidade de mutação e recombinação genética (RABELLO e OLIVEIRA, 2020). Nesse sentido, “os vírus mudam o tempo todo. Mas as circunstâncias nas quais uma mutação se torna uma ameaça à vida dependem das ações humanas" (HARVEY, 2020, p.15).

Diante disso, passado um ano do primeiro contágio, a situação caminha rumo a um avassalador caos, sobretudo no Brasil, com uma política de morte gestada pelo Estado. Estamos em um dos piores cenários desde o início da pandemia com as taxas de contágio crescendo gradativamente e o sistema hospitalar em colapso com falta de UTI (Unidade de Tratamento Intensivo), de oxigênio e insumos necessários. Nesse cenário, outra situação preocupante é a condição da vacinação, cuja campanha, apesar de doses do imunizante serem disponibilizadas prioritariamente aos povos indígenas, não avança devido à má gestão governamental e à disseminação de informações falsas sobre a segurança das vacinas (BENITES et al., 2021).

A conivência do governo com a banalização da morte tem fomentado inúmeras desconfianças, notícias falsas e apatia de uma grande parcela em relação à importância da vacinação. Nesse contexto, a APIB (Articulação dos Povos Indígenas do Brasil) disponibilizou um relatório cobrando ações efetivas e relatando a necropolítica do Governo Federal que desinforma, esconde dados e faz com que os povos indígenas, incluindo os povos de Mato Grosso do Sul, atuem sem nenhum apoio governamental nas campanhas de orientação à vacinação (APIB, 2020). Além disso, as organizações de base indígenas têm sido fator central nas dinâmicas de orientação nas comunidades, no cuidado coletivo e na autogestão territorial.

De fato, no que diz respeito a todo processo de enfrentamento à pandemia, são as articulações e organizações indígenas que têm nos alimentado com ricos exemplos de autogestão, apoio mútuo e solidariedade entre os povos, e mostrado que os caminhos da autonomia e das ações políticas coletivas são a base para o combate à pandemia e a todas as mazelas e violências associadas a essa catástrofe global.

\section{Ações políticas autônomas e autogestão territorial Kaiowá e Guarani frente à pandemia}

A nova pandemia tem demonstrado os efeitos da crise ecológica causada pelo sistema moderno colonial e pelo modelo predatório das 
fronteiras extrativistas, bem como tem demonstrado as faces da fragilidade e instabilidade socioecológica dos sistemas alimentares das agroindústrias, os quais são o eixo da escassez, da precarização das condições de vida e da alta vulnerabilidade que acompanham a destruição dos ecossistemas e territórios. Pensar a dimensão das lutas territoriais indígenas e da pandemia correlacionada às integrações cosmológicas e ecológicas nos proporciona a reflexão que compreende a grande rede de relações em que estamos interligados e as diversas esferas de resistência ambiental e socioterritorial.

Nessa perspectiva, nos pautamos no princípio de pensar nas múltiplas formas de conceber a construção de conhecimentos e a visão de outros mundos, em que o respeito mútuo, a construção de territórios livres e a preservação da diversidade da vida se contrapõem à racionalidade moderna colonial. Ao mesmo tempo em que permite refletir sobre os rumos da humanidade e da luta incessante contra as ações e pensamentos dos "comedores da terra-floresta" (KOPENAWA e ALBERT, 2015; KRENAK, 2019).

Nesse sentido, as transformações das paisagens das florestas tropicais, por meio das narrativas dos povos, tornam-se elementos para as ações políticas em defesa da libertação dos territórios, da construção de autonomias e processos de recuperação ambiental diante do predatismo extrativista. As dimensões das lutas territoriais indígenas correlacionam as integrações e relações ecológicas que reverberam outros mundos, seus agentes e a diversidade de ações políticas pautada na defesa ou retomada dos territórios ancestrais e da biodiversidade.

Nos territórios Kaiowá e Guarani a área em que predominava a mata de forma mais contínua e densa é conhecida também como ka'aguy rusu, e possuía extensão do que hoje seriam considerados vários municípios da região sul do estado - é sobretudo nessa área de mata grande e extensa que a maior parte dos núcleos familiares territorializavam-se em meios aos movimentos dos caminhos estreitos (tape'poi). A mata ou floresta como categoria ampla é composta por diferenciações, patamares e diversos agentes espirituais que compõem seu equilíbrio e o seu bom manejo precisa dos conhecimentos e práticas ancestrais, além do estabelecimento de uma relação harmoniosa junto aos jára. Os jára são considerados os donos e guardiões das espécies e dos lugares. São seres espirituais malfazejos e benfazejos que cuidam dos animais, da flora e dos lugares habitados pelos coletivos, aguçando a sensibilidade daqueles e daquelas que por ali caminham. O universo está repleto de muitos domínios e a cada um deles corresponde um jára específico (JOÃO, 2011).

Esses guardiões compõe os territórios Kaiowá e Guarani junto a outros elementos como a floresta, os rios, a oga pysy (casa de reza) e a kokue (roça), os quais são como agentes que conduzem ao passado e às dimensões espirituais, que fortalecem a memória viva e as novas relações necessárias frente à transformação constante da realidade (BENITES, 2020). Desta forma, esse universo e mundo composto de múltiplas relações e patamares são a base da terra boa (yvy porã), da mata (ka' aguy ygua), e do teko porã (bem viver). 
Conforme Benites (2020), o mundo cosmológico para estes povos é sustentado pelo Ypy (raiz, ancestral, matriz) como relação que dá funcionalidade ao mundo e ao universo e a toda a riqueza e beleza dos mundos e do micro/macro universo. Esse movimento vem do Chiru Renda e resulta em toda a dinâmica do planeta, de toda formação do solo, dos rios, das relações ecológicas e estacionais. Nessa perspectiva, Benites (2014) destaca que o mundo para os povos Kaiowá e Guarani é uma conexão infindável entre o mundo físico e espiritual, que é percebida através da sensibilidade:

As florestas, a terra, o vento, os rios, o sol e a lua, as estrelas, os relâmpagos e toda a manifestação da natureza, têm suas linguagens e vozes, que precisam ser compreendidas e interpretadas. Toda essa diversidade de linguagens da natureza constitui, também, as linguagens dos Kaiowá e Guarani. Estar em constante ligação com esta rede de equilíbrio da natureza é o papel fundamental da nossa atuação, a partir da postura de um corpo espiritualizado (BENITES, 2014, p. 57)

Essas relações e dimensões que compunham os territórios destes povos formavam uma paisagem diversa, tanto pelas ações de manejo social, quanto pela diversidade faunística e florística que confluía nos tekoha. Essa diversidade de relações e multiplicidade territorial foi profundamente transformada, tornando-se, ao longo do tempo, paisagens homogêneas compostas por imensas extensões de monoculturas e pequenos fragmentos de árvores que resistem em meio à homogeneização dos cultivos, ao envenenamento e ao extrativismo. Atualmente, na maior parte da dimensão dos territórios tradicionais, as florestas desapareceram quase que por completo, reorganizando outra paisagem com pastagens, latifúndio e grandes complexos agroindustriais.

Retomar o vigor analítico e político da cosmologia, do território e da biodiversidade a partir do aprendizado com as formas organizativas dos povos, possibilita torná-lo ferramenta de ação para o protagonismo das lutas. De fato, pensar esses elementos cosmológicos, territoriais e ecológicos a partir da ótica dos próprios povos é fundamental para compreender os processos de usurpação dos territórios tradicionais, da biodiversidade e da degradação ambiental gerada pelo colonialismo, pelo Estado e pelas fronteiras extrativistas que impera sobre a região. Isso ainda nos permite evidenciar a simetria e as assimetrias das relações multiespecíficas, das diversas ontologias, mundos e da multiplicidade semântica e de formas de pensar a organização política diante da insegurança e instabilidade territorial dos povos e dos espaços de morte decorrentes do agronegócio.

E frente a esse processo, muitas pessoas de diferentes idades ainda destacam que são o conhecimento ancestral e as práticas tradicionais de cuidado com a terra, associados à recuperação do território, que darão chance à sobrevivência dos povos e dos próprios 
não-indígenas, considerando as consequências perversas do desrespeito e da devastação (KRENAK, 2020).

Contra isso, os povos Kaiowá e Guarani reelaboram as estratégias de luta comunitária e intercomunitária, e as relações com o tekoha através do fortalecimento das lutas anticoloniais pela retomada dos territórios e de ações que contribuam para a gradual recuperação ambiental. Nesse sentido, desde a década de 1970 há um amplo crescimento do fortalecimento da auto-organização dos coletivos a partir das organizações de base e conselhos tradicionais como a Aty Guasu fundamentada na participação direta e ativa dos ñanderu e ñandesy, e diferentes gerações.

A Aty Guasu foi construída sob as bases da luta por reocupação (jeike jey) dos territórios tradicionais a partir da discussão e deliberação ampla e organizada junto às lideranças político-espirituais e às comunidades (BENITES, 2012). Posteriormente, fortaleceram a autoorganização de base das mulheres Kuñangue Aty Guasu e da juventude Retomada Aty Jovem (RAJ). Diante disso, Benites (2014) destaca que os conselhos e as assembleias se constituem como lugares de saberes e fortalecimento étnico-cultural onde são construídas ações políticas coletivas frente às violências e interferências causadas por agentes colonialistas.

Com a reelaboração dos "fatos" e "efeitos do contato" (ALBERT, 2002), esses povos apresentam a resistência indignada, outras formas de ser, viver e de relacionar-se com a fricção de vida. De acordo com Benites (2020, p.20) o objetivo comum em torno da luta pelo tekoha é a busca para fortalecer o ñande reko ete (verdadeiro jeito de ser kaiowá e guarani) e recompor os nutrientes da terra. Nessa caminhada de semear a resistência e a vida nestas terras, a retomada territorial é a base para a recuperação da vegetação nativa e, com ela, as relações cosmológicas, climáticas e ecossistêmicas, que ao longo do tempo, possibilitarão o equilíbrio em um nível elevado. Assim, a terra voltará a ter sensibilidade, com trocas e fluxos de energia como realidade outra vez (BENITES, 2020).

Nesse mesmo sentido, a pesquisadora Célia Xacriabá aponta que a ciência indígena, do segredo e do sagrado, é construída no território, pois o território é cheio de ciência e semeia a multidimensionalidade da subversão dos devires canônicos da ciência ocidental, e se apresenta como ciência construída pela vida e pelos saberes próprios, pelas relações orgânicas e pelas convicções políticas comunitárias. "O território com sua ciência nos alimenta e nos ensina por meio das suas práticas manuais e mentais, ensinando epistemologias" (CORREA, 2018, p. 81). Para a autora:

O saber produzido no centro encontra-se em crise. Algumas universidades já estão se propondo a esse diálogo, há outras que carecem de ampliar e se abrir para essa proposta, e acredito que nós povos indígenas temos muito a contribuir nesse sentido porque o nosso conhecimento não poder ser reduzido como um saber menor ou ser tratado como retórica, somos povos que produzimos nossa própria epistemologia nativa, que é 
alimentada na ciência do território (CORREA, 2018, p.18)

Para mim, de maneira análoga, a ciência do território forma os mais velhos xakriabás, doutores da oralidade e criadores de conceito nativo (CORREA, 2018, p.34).

A luta anticolonial e as formas organizativas ancestrais compõem a semente da esperança e fazem insurgir diversas experiências comunitárias que buscam fortalecer os saberes e práticas tradicionais, bem como buscam semear o retorno dos nutrientes da terra. Nesse sentido, há três experiências fundamentais de serem rememoradas por seu objetivo de valorizar os conhecimentos Kaiowá e Guarani, entre elas: o projeto "Tekoha Xiru Karai: Agroecologia e Bem-viver", do Tekoha Panambizinho, município de Dourados, MS; a Unidade Experimental; e o Viveiro de Mudas da Escola Municipal Indígena Ñandejara Pólo, no tekoha Tey'i Kuê, município de Caarapó, MS.

O projeto Xiru Karai é um território-escola experimental criado em 2010 e iniciado em 2012 como experiência valiosa no âmbito da agroecologia, agrofloresta e soberania alimentar, em que a comunidade associa o manejo à diversidade de espécies vegetais em oposição completa às monoculturas e à precarização territorial. $\mathrm{O}$ pesquisador Anastácio, que conduz o manejo do projeto, ressalta como é fundamental a tecnologia espiritual para plantar e cuidar das espécies de cultivos, em que as plantas são sentidas, respeitadas e cuidadas de forma orgânica e em integração entre todos os seres vivos, a partir da visão de mundo Kaiowá: "a produção também vem de gente, de humano, então a produção é humana, milho é humano, mandioca é humano, porque ela produziu de gente, então elas também se conversam, se falam e também se alegram" (PERALTA, 2017, p. 3).

O Viveiro de Mudas Nativas da Escola Municipal Indígena Ñandejara Pólo iniciou as atividades em 1997 com a finalidade de produção de mudas nativas para recuperação das nascentes das matas ciliares e remanescentes florestais na região de Caarapó. E a Unidade Experimental iniciada em 2001 é um espaço da escola cedido pela comunidade com aproximadamente três hectares, onde realizam o manejo de práticas de cultivo, criação de alguns animais e conservação de microbacias da região. Com essas ações comunitárias a escola tem garantido a permanência de jovens que participam ativamente do desenvolvimento de atividades relacionadas ao cultivo de plantas tradicionais, buscando o fortalecimento e a conservação das sementes crioulas, assim como o reflorestamento do entorno das microbacias.

Essas práticas são articuladas tendo em vista o revigoramento dos sistemas socioecológicos nos territórios e o fortalecimento do manejo no sistema da agroecologia e agrofloresta. Nesse sentido, as ações são pensadas aspirando e inspirando a valorização dos saberes e a conscientização sobre a importância da conservação e recuperação das matas nativas, dos elementos da biodiversidade existentes na reserva e 
no reflorestamento de territórios estratégicos, como as nascentes e microbacias da reserva (RAMIRES, 2016).

Diante disso, no contexto atual, no qual enfrentamos uma das maiores crises de saúde global, a pandemia da Covid-19 tem demonstrado suas faces como uma "das novas cepas de patógenos que subitamente surgiram como ameaça aos seres humanos neste século" (WALLACE, 2020, p. 527) como efeito da brutalidade das monoculturas contra os habitats e territórios de vida. A criação de animais baseada em grande concentração e a agricultura intensiva são a base que aumenta a taxa e o alcance taxonômico do transbordamento de patógenos que vão desde os animais para os da pecuária e destes para as/os trabalhadoras/es desses setores (WALLACE, 2020).

Frente à expansão da doença nos territórios indígenas, as ações de cuidado mútuo com os cultivos e a terra, bem como o processo de autogestão territorial e levantamento das barreiras sanitárias, a partir das ações autônomas construídas pelos Kaiowá e Guarani, têm sido uma das iniciativas mais importantes frente à condição devastadora propagada pela crise sanitária e pela banalização da doença pelo Estado.

\section{A ótica Kaiowá e Guarani: saúde, doença, pandemia e resistências}

Para compreender a resistência dos Guarani e Kaiowá é necessário olhar o mundo através da ótica dos mestres tradicionais, os ñanderu e ñandesy ${ }^{5}$, que teve início desde o início do espaço-tempo (ára ypy), que estabeleceu uma grande lógica (trajetória) da existência na busca da perfeição do ser, através da aproximação sucessiva com os modos de ser das divindades (tekojára kuéra). Assim é o teko araguyje (modo de ser maduro, preparado através dos tempos) que orienta a produção de diferentes gerações e tekoha (aldeia), a partir desses tempos originais, compondo os grandes territórios (tekoha guasu), como o lugar da vida e de todos os seres perfeitos interconectados, formando o teko joja (modo de ser coeso e harmônico).

Através desses olhares, podemos entender que o tekoha é um lugar onde se encontravam e se encontram ainda os diferentes seres/coisas (físicos, biológicos, espirituais) e sistemas (tape) ${ }^{6}$ que permite estabelecer níveis elevados da conexão perfeita, criando o espaço criador (tekoha araguyje) para permitir a germinação dos seres perfeitos, na perspectiva de nivelar-se (oheko arupity) ao modo de ser das divindades. Assim, surgem os mundos e os organismos perfeitos como consequência dos encontros das forças das divindades no mundo terreno, materializadas nos múltiplos ecossistemas que embelezam a face da terra (yvy ombojegua). Por isso, para os ñanderu e ñandesy, os corpos perfeitos (os organismos conhecidos) são produtos do tekoha perfeito refletindo-se neles as forças dos guardiões que energizam a mecânica dos sistemas da vida e do tekoha.

\footnotetext{
${ }^{5}$ Nanderu (líder espiritual masculino) e ñandesy (líder espiritual feminina).

${ }^{6}$ São os caminhos das divindades que se apresentam como múltiplos sistemas terra. 
Porém, além desse mundo perfeito (o mundo que conhecemos) existem outros mundos considerados como imperfeitos (o mundo dos órgãos imperfeitos), compondo a totalidade dos ára (dias, tempo, cosmo), como afirmam as/os mestras/es tradicionais. Estes mundos são as moradas dos seres imperfeitos, onde habitam os grandes guardiões decompositores, os donos das doenças e da morte, que os ñanderu e ñandesy chamam de jeguakaréi ${ }^{7}$, o guardião dos cataclismos universais. No seu domínio estão os grandes gafanhotos, os besouros, os grandes morcegos-dragão (guaruje) e outros grandes destruidores natos da perfeição do cosmo. Dona Amélia, uma grande ñandesy de Panambizinho, afirma que estes seres podem destruir as florestas, os rios e emitir nuvens de doenças mortíferas como forma de dominar o nosso mundo perfeito.

Sabendo dessa totalidade da existência, através das viagens ritualísticas conhecidas como aguyje ${ }^{8}$, as/os mestras/es tradicionais mais poderosas/os, como techakára (revelador), realizam os rituais sagrados de maneira sistemática para orientar as novas gerações a fim de estar em equilíbrio com as forças positivas do tekoha e para manter a perfeição, alinhando-se com o teko araguyje. Para estes líderes, implementar o teko araguyje impede a autodestruição do corpo e do lugar, dificultando a aproximação e o domínio desses grandes guardiões maléficos ao nosso mundo. Diante de tal desafio, os líderes espirituais, em cada aldeia, sempre realizam de maneira contínua os rituais mais sagrados como jerosy (batismo do milho branco), kunumi pepy (ritual de perfuração dos lábios dos meninos), yvy ra'anga (batismo da terra), kokue (roça) e do tekoha (aldeia), como forma de aperfeiçoar sucessivamente a existência, mantendo ligado o modo de ser das pessoas com as divindades.

Estar próximo das divindades no processo da existência produz uma vida sagrada (teko araguyje) e reflete no lugar, formando a aldeia sagrada (tekoha araguyje) como condição da existência. Por isso, o ambiente é visto como o lugar de onde fluem as forças para produzir o corpo (organismo/vida) na sua totalidade. Assim, na ótica dos mais velhos, a vida é produto da presença dos grandes guardiões perfeitos (tekojára kuéra) no tekoha (aqui como ecossistema), porque a conexão dos diferentes sistemas e forças (energias) mecanizadas por estes guardiões estabelece a germinação (ojeasojavo) de diferentes organismos, denominados como ñandua (a capa, modelo de corpos). Cada ser vivo no tekoha é o reflexo da força e da perfeição dos grandes guardiões de caráter perfeito. Por isso, as árvores, os animais, os insetos, os humanos e todos os tipos de seres vivos são representantes do seu próprio guardião no mundo terreno.

Nesta lógica, segundo Lídio Sanches ${ }^{9}$, o corpo humano é a composição da parte perfeita do corpo do ñanderuvusu (divindade

\footnotetext{
${ }^{7}$ Este é um dos guardiões da maldade absoluta, destruidores dos corpos e do cosmos perfeitos. Os ñanderu e ñandesy contam que o seu cocar é feito de fogo e as roupas são manchados de sangue e a sua bebida, também, é feita de sangue de todos os seres viventes e perfeitos criado pelos guardiões de natureza perfeito. ${ }^{8}$ Dona Amélia, uma ñandesy de Panambizinho, conta que o Pa'ichiquito, um dos rezadores poderosos, alcançou o aguyje (teko araguyje), nível elevado da perfeição, permitindo realizar viagens ritualísticas nesses patamares imperfeitos e perfeitos, sendo conduzido pelo seu tekojára denominado como ke’y ára ñe'ẽgatu (o irmão do tempo da boa palavra).

${ }^{9}$ Ñanderu (líder espiritual) que é responsável de cuidar das almas das crianças. 
suprema) e é formado da seguinte maneira: 1) kurusu é a estrutura principal que sustenta o corpo, assemelha-se à cruz e é representada pelo chiru (bastão sagrado) na casa de reza; 2) jeguaka (cocar) compõe a cabeça, o pensamento (mba'ekuaa renda) e a porta da alma, onde a memória está guardada; 3) ku'akuaha (cintura), onde está presente a força do encanto (jepota) de cada ser, principalmente das mulheres; 4) ñandua (capa, modelo de corpos, espécies), que diferencia uma das outras.

A junção destes quatro componentes principais (existem outros ainda) forma o corpo perfeito dos Guarani e Kaiowá para que as almas perfeitas (ayvu) possam realizar o seu repouso, formando a humanidade que conhecemos, assemelhando-se com o corpo do ñanderuvusu. Os ayvu (som primordial, alma) são representados por diferentes pássaros sagrados (guyra ñe'ẽgatu), como papagaio, arara, garça branca e muitos outros, inclusive os já extintos, que trazem e levam as almas das crianças ao mundo dos guardiões. Para que as almas sejam perfeitas, na perspectiva das almas dos guardiões, os corpos (biológicos) devem estar perfeitamente alinhados na ideia do teko araguyje. Caso contrário, podem se tornar maléficos, impuros, metamorfoseando-se em agentes corruptivos, destruidores, como os jeguakaréi.

A ideia da perfeição objetiva a estruturação da aldeia e dos corpos de nível muito elevado para fluir, desde o mundo dos guardiões perfeitos (tekojára kuéra), a potência da humanidade que chamamos de teko araguyje (modo de ser maduro, preparado através dos tempos), ou, modo de ser das divindades. Acontece que os guardiões de caráter imperfeito, como os destruidores, buscam devorar este mundo para se metamorfosear em perfeição - por serem de natureza maléfica, acabam gerando decomposição e, assim, surgem as doenças e a morte. E é na luta dos organismos perfeitos para manter a sua perfeição diante dos devoradores que se estabelecem as etapas da vida, como o nascimento, a reprodução, a velhice e a morte, como, também, a sua resistência por meio da interdependência entre os seres, refletindo em um ecossistema.

Para os ñanderu, as doenças surgem quando estas conexões ecossistêmicas estão enfraquecidas e os seres maléficos acabam se fortalecendo, decompondo as estruturas dos corpos, iniciando o seu domínio no mundo terreno. Para resolver essa situação, os ñanderu entoam poderosos canto-reza para pedir ao dono das doenças para retirar o seu domínio no mundo da humanidade. Estes cantos-reza são os ñevanga, um conjunto de cantos para os donos das doenças. Além disso, esses cantos-reza absorvem as forças das plantas e dos alimentos sagrados da roça, contribuindo no restabelecimento da força do corpo porque tais organismos retém as forças dos seus guardiões e, no processo da nutrição, reestabelecem a força das conexões. Daí a importância das plantas medicinais e dos rituais sagrados para combater o efeito dos donos das doenças através do diálogo e das ações que os repelem através das forças das plantas.

Por isso, muitos ñanderu e ñandesy afirmam que o equilíbrio da terra é assegurado pelo canto-reza (porahéi), uma metalinguagem pela qual todos os guardiões, tanto os perfeitos quanto os imperfeitos, são 
compreendidos e, com isso, se comunica para a manutenção do equilíbrio da terra e do universo. Este canto-reza foi criado no início do tempo, quando ñanderuvusu caminhava no cosmo fazendo aliança política com diversos seres desconhecidos para compor o ára que conhecemos - nesta comunicação original criou-se o canto-reza, pelo qual todos os seres do cosmo são conectados. É por isso que essa comunicação é vista como uma metalinguagem (cantos originais, as palavras antigas). Hoje, nas aldeias, estas metalinguagens estão com os ñanderu e ñandesy, através dos quais realizam um diálogo com os seres divinos, assegurando a perfeição e gerando o equilíbrio do nosso mundo.

Este equilíbrio mediado pelos ñanderu e ñandesy nas aldeias é quebrado com a chegada da sociedade não-indígena, os karai kuéra (os brancos, o mundo moderno). Pela ânsia de produzir riqueza capitalista, destruíram as florestas, contaminaram os rios, aplainaram as terras e dizimaram todos os tipos de seres vivos que viviam em uma grande rede de conexão, onde as forças fluíam como um rio. Por isso, os guardiões perfeitos se afastaram, distanciando-se do tekoha (aldeia) e da yvy (terra), porque se tornou estéril, árida, acima de tudo corrosiva (pela poluição dos agroquímicos) ${ }^{10}$, ausentando todos os tipos de seres perfeitos. Esta grande ausência permite a emergência de diferentes doenças, gerando grandes pandemias, como a chegada do coronavírus, desafiando toda a humanidade com seu poder de contaminação e fatalidade.

Para as lideranças tradicionais estamos em um novo tempo (ára), o fim dos tempos (ára paha), o tempo em que os guardiões perfeitos que seguravam o equilíbrio da terra estão se afastando e o efeito será uma escala progressiva da chegada de diferentes doenças de potência maior e mais destrutivas que desafiarão cada vez mais a humanidade. Assim, para os ñanderu e ñandesy, estende-se entre nós uma fumaça nebulosa de doenças incuráveis e poderosas que desafiam a ciência do homem branco, como, também, as próprias lideranças espirituais Guarani e Kaiowá. Este desafio é agravado porque nos dias de hoje as forças do tekoha estão enfraquecidas e as plantas medicinais mais potentes já não se encontram devido à devastação feita pelos karai (brancos).

Essa pandemia que enfrentamos na atualidade é apenas o prenuncio da chegada de outras e maiores doenças desconhecidas e destrutivas que podem alterar o rumo da humanidade se esta não mudar a sua postura predatória, que vem alterando diferentes tekoha dos guardiões que povoam invisivelmente (para nós) o planeta Terra. Com a maldade humana em acessão, o mundo se torna um espaço corrosivo, impuro, repugnante como aterro sanitário (yvy itapuru'a), emitindo odores repulsivos e afastando os guardiões perfeitos que asseguravam o equilíbrio e a perfeição da terra. Assim, os guardiões maléficos aproximam-se cada vez mais da humanidade emitindo e liberando doenças cada vez mais potentes porque a maldade humana, em especial

\footnotetext{
${ }^{10}$ As forças originais da terra são resultado da presença dos guardiões que levaram tempo suficiente para produzir diferentes seres da vida. Porém, com a manipulação do homem branco, a força da terra é sintética, o que permite apenas produzir plantas de monocultura, conforme o seu objetivo, impedindo o nascimento de outras plantas originais do seu habitat.
} 
a dos não indígenas, polui e decompõe todos os lugares em níveis diferenciados, abrindo caminhos para o cataclismo global.

$\mathrm{Na}$ visão dos Guarani e Kaiowá, neste mundo imperfeito, além do jeguakaréi (guardião da destruição, dos sanguinários), estão o chiru kamba (guardião da escuridão), kurupiry (donos das doenças) e aña (guardião da maldade absoluta). Os grandes techakára (reveladores) contam que nestes patamares a visão é tão perturbadora/assustadora que se os ñanderu estiverem realizando as primeiras viagens ritualísticas ficam em grande temor porque são acostumados a enxergar o mundo perfeito (o nosso mundo) e quando enxergam a totalidade do cosmo percebem que a nossa compreensão é apenas uma parcela da totalidade do ára (cosmo). Este cosmo imperfeito pode se estender ao nosso mundo, refletindo-se em desordem da estrutura perfeita porque o próprio homem branco destrói o nosso mundo perfeito (natureza, ecossistema).

Com a decomposição das estruturas dos sistemas dos tekoha perfeitos pela presença dos não indígenas, de maneira predatória, chegase ao nível extremo que atinge os corpos biológicos, já que os fluxos das forças originais da terra não são mais absorvidos pelos organismos do tekoha. A destruição do tekoha (ecossistema, natureza, meio ambiente) reflete no corpo Guarani e Kaiowá provocando desequilíbrio, que podemos entender como doença. A doença é o mba'asy (dores) e está ligada diretamente ao tekoha: se o tekoha está doente, o corpo fica doente e vice-versa. Além disso, o mba'asy não é apenas sentido no nível biológico do corpo, mas, também, na alma (ayvu) das pessoas, como resultado do desajuste do equilíbrio social que a própria destruição do tekoha provoca.

Por isso, os Guarani e Kaiowá buscam reaver seu tekoha tradicional para recompor a força da terra (re) implementando o teko araguyje, como forma de limpar as impurezas impostas pela sociedade não indígena. Essas impurezas permitem a nebulização das doenças no tekoha, agravando a destruição da estrutura do equilíbrio entre os seres vivos e os guardiões. Nessa nova recomposição das forças será necessário dialogar com os saberes e modos de ser não indígena, aquelas/es que contribuem para a reedificação do tekoha, no horizonte do teko araguyje. Além disso, para esta recuperação da terra, o alicerce será a memória dos mais velhos como ñanderu e ñandesy, porque são os guardiões desde mundo perfeito criado pelo ñanderuvusu no início do espaço-tempo (ára уру).

A recomposição das forças originais da terra permitirá a reaproximação dos grandes guardiões perfeitos e a possibilidade de afastar os donos das doenças para que o tekoha volte ao seu rumo original, permitindo a perpetuação da saúde e o bem-estar como ocorria antes da chegada da sociedade não indígena. Pela perspectiva dos ñanderu e ñandesy, com as terras recuperadas os corpos dos Guarani e Kaiowá serão recompostos também, porque a força do tekoha reflete no corpo para se transformar em agente multiplicador da diversidade local, como as sementes em uma floresta.

Manter e fortalecer a diversidade local, entre elas os corpos dos Guarani e Kaiowá, é o grande objetivo, pois permite o trânsito dos 
grandes guardiões que se transformaram em estrutura perfeita (tape), devido à sua harmonia (teko joja) e ao sistema peculiar do lugar, recompondo, assim, as energias do tekoha (ecossistêmicas e espirituais).

\section{Considerações finais}

A proposta do trabalho foi compartilhar reflexões conjuntas sobre as dimensões da cosmologia, da biopolítica e da geopolítica da pandemia permeando aspectos que demonstrem as múltiplas estratégias de resistência dos povos Kaiowá e Guarani frente ao agronegócio e no enfrentamento à Covid-19. Assim, em um amplo processo de precarização e fragmentação territorial, esses povos constroem resistências marcadas por estratégias baseadas na auto-organização comunitária, intercomunitária, no fortalecimento da espiritualidade e na valorização dos conhecimentos tradicionais.

Toda essa multidimensionalidade de ações e reações semeia um caminho de autodeterminação política, autonomia e expressão da diversidade de saberes e modos de ser como léxicos teóricometodológicos. Para estes povos, a ciência indígena, construída através dos saberes cosmológicos tradicionais, tem sido eixo fundante das lutas territoriais atuais.

Assim, refletimos que a ligação entre o agronegócio e a pandemia nos territórios Kaiowá e Guarani é exposta a partir de narrativas que ressaltam a dizimação da vegetação nativa, da brutal perda da biodiversidade, da destruição de nascentes e rios e do profundo envenenamento do solo e fragmentação dos territórios, em razão do lucro e da racionalidade moderna-colonial, ou, ainda, da cultura do mono. Esse enredo perverso fomenta a degradação ecológica através de um sistema político-econômico que tem como pilares a desumanização e subalternização para concentração e acumulação da riqueza de alguns poucos exploradores.

A pandemia causada pelo novo coronavírus surgiu do profundo saque à biodiversidade, aos territórios e aos habitats saudáveis, demonstrando a relação intrínseca entre populações humanas e o ambiente. Nesse sentido, nos inspiramos e esperançamos através da cosmologia, do conhecimento tradicional Kaiowá e Guarani e da luta pelo tekoha como estratégia de manutenção e valorização do modo de vida baseado no bem viver, o qual somente será possível através do processo de retomada de suas terras tradicionais, por meio da luta autônoma e auto-organizada. Esse processo semeará condições que possibilitarão a recuperação ecossistêmica e espiritual dos tekohas e dos corpos Kaiowá e Guarani. 
Espaço Ameríndio

\section{Referências bibliográficas}

ALBERT, Bruce. O ouro canibal e a queda do céu. In: ALBERT, Bruce; RAMOS, Alcida Rita (Org.). Pacificando o branco: cosmologias do contato no norte amazônico. São Paulo: Ed. Unesp, 2002.

AMADO, Luiz Henrique Eloy; RIBEIRO, Ana Maria Motta. Panorama e desafios dos povos indígenas no contexto de pandemia do Covid-19 no Brasil. Confluências - Revista Interdisciplinar de Sociologia e Direito, v. 22, n. 2, p. 335-360, 2020.

ARTICULAÇÃO DOS POVOS INDÍGENAS DO BRASIL. (APIB). Panorama geral da COVID, 2020. Disponível em http://emergenciain-digena.apib.info/dados covid19/

BENITES, Eliel. Oguata Pyahu (Uma Nova Caminhada) no processo de desconstrução e construção da educação escolar indígena da aldeia Te'ýikue. 2014. 165f. Dissertação (Mestrado em Educação). Universidade Católica Dom Bosco - UCDB, Campo Grande, MS, 2014.

BENITES, Eliel. Tekoha Ñeropu'ã: aldeia que se levanta. Presidente Prudente: Revista Nera, v. 23, n. 52, p. 19- 38, dossiê., 2020.

BENITES, Eliel; GISLOTI, Laura Jane; ROQUE, Fabio de Oliveira. Brazil: Boost COVID-19 vaccine uptake in Indigenous people. Nature, v. 591, p. 369, 2021.

BENITES, Tonico. Trajetória de luta árdua da articulação das lideranças Guarani e Kaiowá para recuperar os seus territórios tradicionais tekoha guasu. Revista De Antropologia da Ufscar, v. 4, n. 2, p. 165-174, 2012.

CHAMORRO, Graciela; COMBÈS, Isabelle. Povos indígenas em Mato Grosso do sul: História, culturas e transformações sociais. Revista Caminhos, v. 17, n. 1, p. 397-403, 2019.

CORREA, Célia Nunes. O Barro, o Genipapo e o Giz no fazer epistemológico de Autoria Xakriabá: reativação da memória por uma Educação Territorializada. Dissertação (Mestrado em Sustentabilidade junto a Povos e Terras Tradicionais) - Universidade de Brasília, Brasília-DF, 2018.

GARNETT, Stephen T. et al. A spatial overview of the global importance of Indigenous lands for conservation. Nature Sustainability, v. 1, n. 7, p. 369-374, 2018.

HARVEY, David. Política anticapitalista em tempos de covid-19. In: DAVIS, Mike, et al. Coronavírus e a luta de classes. Terra sem Amos: Brasil, 2020, pp. 13-23.

JOÃO, Izaque. Jakaira Reko Nheypyrũ Marangatu Mborahéi: origem e fundamentos do canto ritual Jerosy Puku entre os kaiowá de Panambi, Panambizinho e Sucuri'y, Mato Grosso do Sul. 2011. Dissertação (Mestrado em História) - Universidade Federal da Grande Dourados, Dourados, MS, 2011. 
Espaço Ameríndio

KOPENAWA, Davi; ALBERT, Bruce. A queda do céu. Palavras de um xamã Yanomami. São Paulo: Companhia das Letras, 2015.

KRENAK, Ailton. Paisagens, territórios e pressão colonial. Espaço Ameríndio, v. 9, n. 3, p. 327, 2015.

KRENAK, Ailton. Ecologia Política. Ethnoscientia, v. 3, n. 2, 2018.

KRENAK, Ailton. Ideias para adiar o fim do mundo. Companhia das Letras, 2019.

KRENAK, Ailton. A vida não é útil. São Paulo: Companhia das Letras, 2020.

MARTINS, Elemir Soare.; MONFORT, Gislaine C.; GISLOTI, Laura J. Conhecimentos Indígenas, Autonomias e Lutas Anti-Coloniais Kaiowá E Guarani Contra A Necropolítica e o Agronegócio. Revista Terra Sem Amos, v. 2, p. 1-5.

MBEMBE, Achille. Necropolitic, Public Culture, v. 15, p. 11-40, 2003.

MBEMBE, Achille. Necropolítica: Biopoder, Soberania, Estado de Exceção, Política da Morte. São Paulo: N-1edições, 2018.

MONFORT, Gislaine C.; GISLOTI, Laura J. Necropoder e crimes socioambientais do agronegócio, lutas anticoloniais e resistências socioterritoriais kaiowá e guarani. In: CLACSO (ORG.). Boletín Geocrítica Latinoamericana. Ecología política contra el saqueo de la naturaliza, 2020, p. 138-157

ORTIZ Amado Insfrán; MEZA, Maria José Aparicio. La destruccion de los ecossistemas como paradigmas de la civilizacion moderna: recogiendo frutos. In: MARQUES, J.; DIAS-LIMA, A. (Org.). Ecologia humana \& pandemias: consequência, as da COVID-19 para o nosso futuro. Bahia: SABEH, 2020, p. 88-108.

PAVÃO, Sônia et al. Plantas medicinais dos povos kaiowá e guarani como possível prática complementar no enfrentamento dos sintomas da covid-19. Revista Brasileira de Agroecologia, v. 15, n. 4, p. 14, 2020.

PERALTA, Anastácio. A Agroecologia Kaiowá: tecnologia espiritual e bem viver, uma contribuição dos povos indígenas para a educação. Revista MovimentAção, v. 4, n. 6, p. $1-19,2017$.

PEREIRA, Levi Marques. Os kaiowá em Mato Grosso do Sul: módulos organizacionais e humanização do espaço habitado. Dourados: Ed. UFGD, MS, 2016. $128 \mathrm{p}$.

RAMIRES, Lídio Cavanha. Processo próprio de ensino-aprendizagem Kaiowá e Guarani na Escola Municipal Indígena Ñandejara Pólo Reserva Indígena Te’ýikue. 124f. Dissertação (Mestrado em Educação) - Universidade Católica Dom Bosco, Campo Grande, 2016.

RABELLO, Ananza Mara; OLIVEIRA, Danielly Brito de. Impactos ambientais antrópicos e o surgimento de pandemias. Unifesspa: Painel Reflexão em tempos de crise. 
Espaço Ameríndio

mai.

2020.

Disponível

em:

$<$ https://acoescovid19.unifesspa.edu.br/images/conteudo/Impactos_ambientais_antrópic os_e_o_surgimento_de_pandemias_Ananza_e_Danielly.pdf $>$ Acesso em 05 maio 2021.

SHIVA, Vandana. Monoculturas da Mente: Perspectivas da Biodiversidade e da Biotecnologia. São Paulo: Gaia, 2003.

VALIENTE, Celuniel. Breve descrição sobre os kaiowá e guarani na graduação e pósgraduação. Tellus, v. 18, n. 36, p. 193-205, 2018.

VALIENTE, Celuniel Aquino. Modos de produção de coletivos Kaiowá na situação atual da Reserva Indígena de Amambai, $M S$. 2019. 192 f. Dissertação (Mestrado em Antropologia), Universidade Federal da Grande Dourados, Dourados, 2019.

VERON, Valdelice. Tekombo'e Kunhakoty: Modo de viver da mulher Kaiowá. Centro de Desenvolvimento Sustentável. Dissertação (Mestrado Profissional em Sustentabilidade Junto a Povos e Terras Tradicionais). Universidade de Brasília, 2018.

WALLACE, Robert. Pandemia e agronegócio: doenças infecciosas, capitalismo e ciência. Tradução: Allan Rodrigo de Campos Silva, São Paulo: Elefante, 2020. 